\title{
Bending Fatigue Tests of Carbon Fiber Reinforced Epoxy Resin Composite Plates
}

\section{Péter Szuchy, Tamás Molnár, István Bíró, Sándor Csikós, László Gogolák, József Sárosi}

Department of Technology, Faculty of Engineering, University of Szeged, Mars tér 7, 6724 Szeged, Hungary

e-mail: szpeter@mk.u-szeged.hu, molnart@mk.u-szeged.hu, dekan@mk.u-szeged.hu, csikos-s@mk.u-szeged.hu, gogolak@mk.u-szeged.hu, sarosi@mk.u-szeged.hu

\begin{abstract}
This paper introduces the results of the bending fatigue tests of composite materials manufactured with different numbers of carbon fiber layers, embedded in an epoxy resin. The novel fatigue test machine, with crank mechanism, is presented and was optimized for partial dynamic loads. During the tests, half of the specimens were examined only for tensile strength, the other half were tested first, by fatigue tests, with at least 10 million bending cycles and afterwards using tensile tests. We studied the differences between the tensile strengths of the two groups and the influence of the number of reinforcing material layers in the results. Different kinds of ruptures were detected and categorized as Grip ruptures, Neck ruptures, Whiskers ruptures and Double ruptures. Results of an unplanned excess load is also presented, where cracks appeared along the reinforcing fibers and the tensile strength decreased significantly.
\end{abstract}

Keywords: composite; carbon fiber; epoxy resin; fatigue; tensile test; crank mechanism; optimization for partly dynamic load

\section{Introduction}

In the $21^{\text {st }}$ Century, the development of technology requires increase of capability of artificial engineering materials. The continuously developing composite materials are significantly enlarging the toolbox of engineers, and with the application of them some of the engineering structures and equipment can operate with higher efficiency and longer lifetime [1]. From this point of view, the polymer structural materials have outstandingly important role and combining them with other polymers, metals or ceramics heavy-duty composite structures can be produced [2]. Polymer composites are complex systems, typically, one of the components, called the reinforcement, takes the mechanical loads, the other is the bedding material, called the matrix. The main objective of the latter, is proper 
load distribution and protection of the reinforcing materials, against external influences. The adhesive connection between the two composites needs to be strong, so that the material can withstand high loads without failure, even in case of large number of repetitive loads. These materials are characterized by relatively low density, alongside their excellent mechanical properties, so their usage can bring lower tare weight of a given structure. This reduction of weight can go hand in hand with significant energy- and cost-savings, in almost every sector of transport [3].

A significant part of the polymer components are subjected to a permanent load and this load, is often cyclical. Therefore, the viscoelastic behavior of polymers is especially important because, as a result of this, their response for the long term load is not static. In engineer practice the design for stress is an accepted and widespread practice, but in the case of polymers, it is not enough, the change of deformation in time has to be considered as well, especially for the case of permanent loads. The deformation of thermoplastic polymers can be divided into three deformations, regardless of the maximum load [4]:

- Instantaneous

- Delayed elastic

- Permanent deformation

The creep and stress-relaxation tests of polymers are widespread, however, all the effects of the different reinforcing materials are not revealed yet that is especially true in case of the nano- and hybrid-composites. The traditional microfibers and the nano-scale reinforcing materials can have a possible impact on the creep as well. The rate of creep and stress-relaxation can be lower as the reinforcing materials take a part of the load and reduce the deformation of the composites, pushing its viscoelastic behavior in the shade. Besides that, the reinforcing materials usually do not have creep [5].

There are many factors influencing the behavior of material during fatigue test, so the proper choice of testing parameters is essential. It is particularly true in case of the thermoplastic polymers where significant warming of specimen can be observed many times during the tests due to the higher deformation and inner friction. So the EN ISO 13003 standard prescribes that the temperature has to be registered continuously or at the examination such a frequency has to be chosen which does not increase more than $10 \%$ the temperature of the specimen. It can happen at composites that the rise of temperature enlarges the lifetime, as the temperature of the specimen can overstep the glass transition, due to which the polymer becomes tougher. The presence of the fibers also influences the fatigue, these effects are mostly known nowadays, but in case of hybrid composites only moderate knowledge is available [6].

In the case of fiber-reinforced polyamide 6 matrix composites, initially, Horst and Spoormaker described the failure process. Based on the fatigue test the failure 
process was divided into the following parts. During the fatigue, the binding between the fiber and the matrix always break up, first at the ends of the fibers, because these are stress collecting points where locally high shearing stress appears. In certain cases, hollowing can occur at the middle section of fiber, because of the buckling of the fiber, when the matrix cannot distribute it flexibly [7]. The fracture of the fiber is less prevalent during the fatigue tests. The microcracks in the matrix grow along the fibers, after their emergence, thus, the matrix increasingly, assumes the load. In the surroundings of the fiber, the matrix deforms plastically, while the cracks become larger and the ends link to each other, creating a growing surface which is bonded by polymer chains or fibers. When the linked cracks reach a critical dimension, the stress reaches the tensile strength in the cross section of the polymer and a brittle fracture occurs.

In the professional literature, different constructions can be found to fatigue composite materials. Ueki developed the methodology for high-speed fatigue testing, especially for resin materials, including fiber-reinforced composites [8]. The temperature of specimen was controlled by external cooling. To confirm the validity of the devised high-speed-testing method, a completely reversed bending test at $1 \mathrm{~Hz}$ was also performed with identical specimens. There are agreement between the obtained results for this reason the fatigue tests in high cycle region of resin and composites can be evaluated in a very short time.

Kulkarni et al. in [9] presented the development of a plane bending fatigue testing machine for composite material. The proposed machine is simple in design and economical. An eccentric cam and connecting rod arrangement is done for the fully reserve bending motion of the work piece.

Van Paepegem and Degrieck developed an experimental setup for bending fatigue [10]. A numerical method is presented as well, which allows one to describe the degradation of the composite specimen during its fatigue life. Authors noted that these bending tests yield important additional information that cannot be recovered from conventional tension fatigue tests. Landge et al. also developed an experimental setup for bending fatigue [11]. The setup is inexpensive, efficient and does not requires a lot of space, like the conventional fatigue testing machines available in the market.

\section{The Fatigue Test Machine}

The first step of the project was developing and manufacturing a fatigue test machine that can produce 10 million load cycles per specimen in a reasonable time. In the beginning of the development, an extant Brüel \& Kjaer shaker had the key role, but at the end a crank mechanism was executed (Fig. 1). At this point in the construction, the linear guideway, at relative high speed and the dynamic balancing, caused the main problems. For the linear guideway, sinter-bronze 
bearing bushes were choosen. Due to the lubricant pressed into its porous material, during production, the maximum sliding speed of this kind of sliding bearing is $10 \mathrm{~m} / \mathrm{s}$, which exceeded our needs.

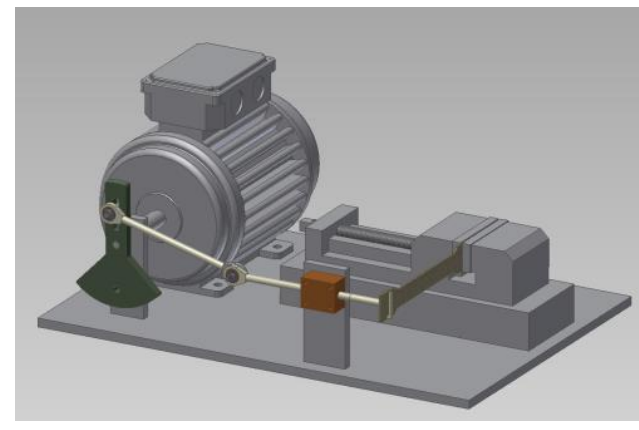

Figure 1

3D model of the bending fatigue test machine with crank mechanism

Two pieces of 08.12.20 (8 mm inner diameter, $12 \mathrm{~mm}$ outer diameter, $20 \mathrm{~mm}$ length) bushing was applied for the horizontal support, and the housing was manufactured at the Faculty. The highest surface pressure $\left(\mathrm{q}_{\mathrm{f}}\right)$ of the bushings was calculated by the loading model of Fig. 2 .

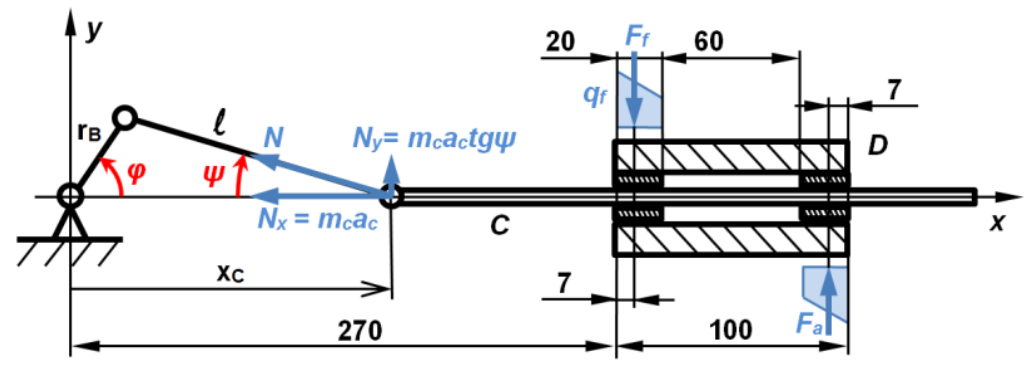

Figure 2

Loading model of the bushes

The moments of rod $\mathrm{C}$ are written to the intersection of shaft $x$ and line of action of force $F_{a}$, where $F_{f}$ and $F_{a}$ are the apparent concentrated forces of the bushings:

$0.086 \mathrm{~m} F_{f}-\left(0,363 \mathrm{~m}-x_{c}\right) m_{c} a_{c} \operatorname{tg} \psi=0$

The maximum load $F_{f}$ can be overestimated by the longest arm of the force, the maximum angle of the crank arm $(\psi)$ and the highest angular velocity:

$F_{\text {fmax }}=\frac{0.357 \mathrm{~m} * 0.1614 \mathrm{~kg} * 0.05 \mathrm{~m} *(2 \pi 10 \mathrm{~Hz})^{2} * t g 15^{0}}{0.086 \mathrm{~m}}=35.5 \mathrm{~N}$

So the maximum surface pressure on the $8 \mathrm{~mm}$ inner diameter, $20 \mathrm{~mm}$ long bushing: 
$q_{f}=\frac{4 * F_{\text {fmax }}}{3 * 160 \mathrm{~mm}^{2}}=0.3 \mathrm{MPa}$

At the first model with crank mechanism the previously used disk was taken over, in which there was only one radial slot for setting the bending deflection's size of the specimen. But the accelerations of the crank mechanism were so high that a partly dynamic balancing of the masses was necessary, and the best location of it was on the disc (Fig. 3).

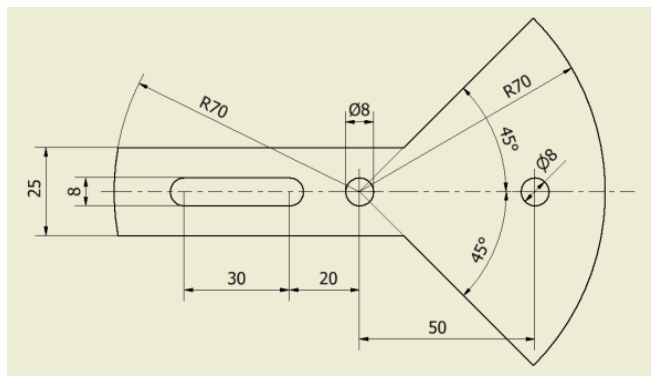

Figure 3

Disk of the crank mechanism optimized for partly dynamic load

The disk can be divided to two parts (see Fig. 3): the right one consists of a circular sector with $90^{\circ}$ central angle, the other part is the rest of the disc, named stick. The sector's center of mass, measured from the middle point of the circle in case of $r=70 \mathrm{~mm}, \alpha=90^{\circ}$ (without the hole):

$r_{e}=\frac{2}{3} \frac{r \sin ^{\alpha} / 2}{\alpha / 2}=\frac{2}{3} \frac{70 \mathrm{~mm} \frac{\sqrt{2}}{2}}{\frac{\pi}{4}}=\frac{4}{3} \frac{70 \mathrm{~mm} \sqrt{2}}{\pi}=42 \mathrm{~mm}$

The mass of the quarter circle if the width of the disc is $\mathrm{v}=10 \mathrm{~mm}$ :

$m_{e}=\frac{r^{2} \pi}{4} v \rho=\frac{(0.07 \mathrm{~m})^{2} \pi}{4} 0.01 \mathrm{~m} 7850 \frac{\mathrm{kg}}{\mathrm{m}^{3}}=0.30 \mathrm{~kg}$

The kinetic model of the crank mechanism with point-like masses without extension is introduced by Fig. 4:

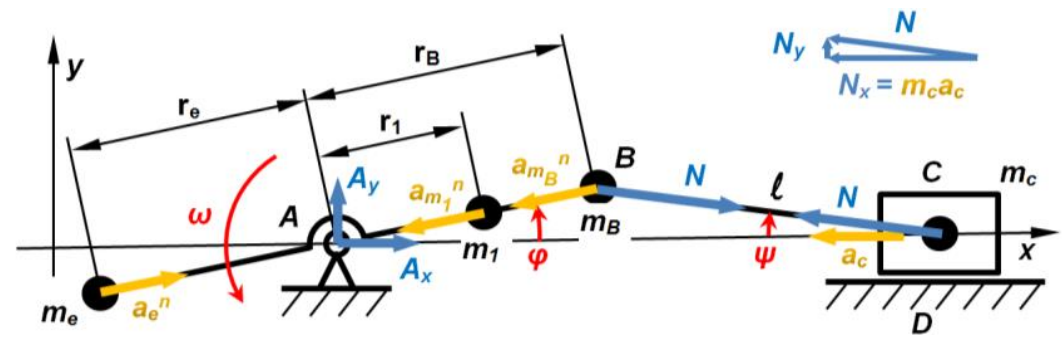

Figure 4

Kinetic model of crank mechanism 
At the kinetic model of crank mechanism the masses are considered without extension: $m_{e}$ is the mass of the circle section part, $m_{1}$ is the mass of the stick, $m_{B}$ is the mass of pin, bearing and housing connected to the disc, together with the half of the crank-arm, $m_{C}$ is the mass of the coupling rod with the connected bearing, housing and the other half of the crank-arm. As an engineering approximation the angular velocity of disc $\omega$ is considered constant. Accordingly, the relationships are as follows:

$r_{B} \sin \varphi=l \sin \psi$

$\psi=\arcsin \frac{r_{B}}{l} \sin \varphi$

$N=\frac{m_{C} a_{C}}{\cos \psi}$

The kinetic equations of movement written to $\mathrm{x}$ and $\mathrm{y}$ direction according to D'Alembert:

$-m_{e} r_{e} \omega^{2} \cos \varphi+m_{1} r_{1} \omega^{2} \cos \varphi+m_{B} r_{B} \omega^{2} \cos \varphi-m_{C} a_{C}+A_{x}=0$

$-m_{e} r_{e} \omega^{2} \sin \varphi+m_{1} r_{1} \omega^{2} \sin \varphi+m_{B} r_{B} \omega^{2} \sin \varphi-m_{C} a_{C} \operatorname{tg} \psi+A_{y}=0$

and so the $\mathrm{x}$ and $\mathrm{y}$ directional force components awakening in the point $\mathrm{A}$ :

$A_{x}=m_{C} a_{C}+\omega^{2}\left(m_{e} r_{e} \cos \varphi-m_{1} r_{1} \cos \varphi-m_{B} r_{B} \cos \varphi\right)$

$A_{y}=m_{C} a_{C}+\omega^{2}\left(m_{e} r_{e} \sin \varphi-m_{1} r_{1} \sin \varphi-m_{B} r_{B} \sin \varphi\right)$

According to (14) and (15) equations a numerical analysis was executed, on which base an optimization was implemented. The goal of the optimization was bringing to the same level the maximum value of the $\mathrm{A}_{\mathrm{x}}$ and $\mathrm{A}_{\mathrm{y}}$ bearing force components. Fig. 5 presents the changes of the bearing force components during a whole rotation beside optimized parameters. $B_{y}$ increasing the mass me of the counterweight, the maximum value of the force component $A_{x}$ decreases, and the maximum value of $A_{y}$ increases. As the counterweight decreases, the consequence is converse.

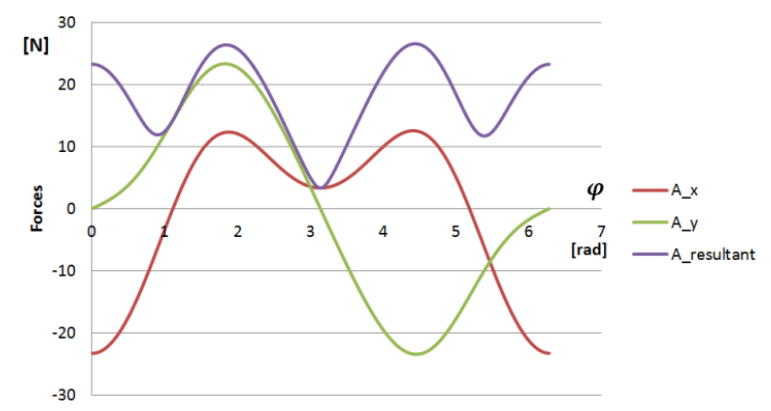

Figure 5

Changes of force $\mathrm{A}$ and $\mathrm{x}, \mathrm{y}$ components of it during a whole rotation 
The working test of the fatigue test machine with the partly dynamic balanced crank mechanism was successful. For rotation control of the electric motor a frequency converter was applied. For counting the number of bending an optical sensor with a CPU was installed.

\section{Fatigue and Tensile Tests}

The tests were determined as bending fatigue and tensile tests of composite materials with different number of reinforcing laminates. Since the required 10 million bending movements for one specimen could be accomplished in about two weeks by the fatigue test machine, we could not aim to achieve statistical quantity of tests, we rather tried to find orientations for latter research that cover the following:

- Effects of bending fatiguing for the tensile strengths

- Effects of the number of reinforcing laminates for the tensile strength without fatiguing

- Effects of the number of reinforcing laminates for the tensile strength after fatiguing

The composite material plates with four different thicknesses were manufactured with vacuum-infusion technology. The fiber reinforcement was ensured by $3,4,5$ or 6 laminations of twill of carbon fiber (each lamination had the same $200 \mathrm{~g} / \mathrm{m} 2$ ), embedded into epoxy resin. The standard flat tensile test specimens were cut out of the plates by milling machine. The thickness of the specimen was measured at three points of each: at the both neck and in the middle, then probe tensile tests were executed. Finally, half of the specimens were examined by fatigue test then tensile tests, the rest of them were tested only by tensile test as a control group.

\subsection{Tensile Tests without Fatiguing}

The first probe tensile test was executed on specimens with three different thicknesses ( $1^{\text {st }}: 3$ layers, $2^{\text {nd }}: 4$ layers, $3^{\text {rd }}: 6$ layers.) and these presented immediately some interesting findings which also occurred later in the examinations (Fig. 6):

1) Grip rupture (Fig. 6b): at one of the tests the rupture proceeded from the grip jaws.

2) Neck rupture: the normal rupture (not Grip rupture) always appeared at the neck section (and only once at the long narrow section).

3) Whiskers rupture (Fig. 6c), at neck ruptures long fiber whiskers remain on both brinks of the specimen. 
4) Double rupture: in case of the thick, 6 reinforcing laminated composite a double rupture happened: the specimen broke at once at both neck.

The most important observation was the Grip rupture which was induced by the crunch of the gripping jaws, destroying the specimen and the examination in most cases. We used several gripping methods in order to avoid this failure (aluminum or composite plates between the specimen and the jaws) but the attempts were barren of results, so this problem brought many annoyances during the subsequent examinations. The second observation, the Neck rupture derives probably from the fiber damage made by the milling that could impair the longitudinal fibers at the neck, just like a "crack on the texture" effect.

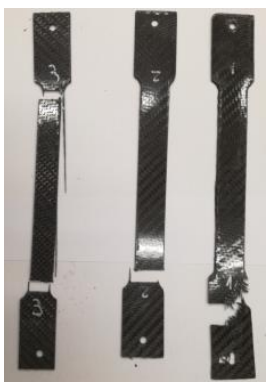

First probe tensile tests (6a: left), Neck rupture $(6 \mathrm{~b}$
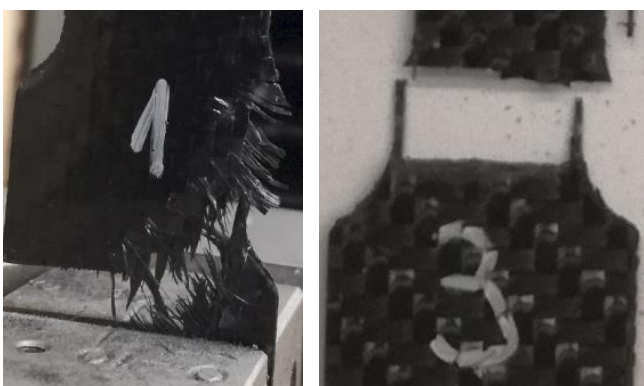

Figure 6

The Whiskers rupture appears as longitudinal fibers ripped out of the twill, the best chance the peripheral fibers have, is where the cross fibers cannot keep them in the texture. The fourth phenomenon is the double rupture that occurred later, in all of the 6 layer composites specimens' tensile tests, without fatiguing. We have not tried to find the explanation for it, but it may have a correlation to the phenomenon of spaghetti break into three parts (Feynman's puzzle).

For examining the effects of the number of reinforcing laminates in the tensile strength, without fatiguing, the best is comparing the result of the tensile tests of the 3 and 6-layer composite specimens (Table 1).

Table 1

Tensile test results of 3 and 6-layer composite specimens without fatigue tests

\begin{tabular}{|c|c|c|c|c|c|c|c|}
\hline Without & Code & $\mathbf{F m}$ & $\mathbf{R m}$ & \multirow{2}{*}{$\begin{array}{l}\text { Without } \\
\text { fatig. test }\end{array}$} & Code & $\mathbf{F m}$ & $\mathbf{R m}$ \\
\hline fatig. test & & {$[\mathrm{N}]$} & {$[\mathrm{MPa}]$} & & & {$[\mathrm{N}]$} & [MPa] \\
\hline \multirow{4}{*}{3 layer } & $1 \mathrm{~A}$ & 3921,5 & 248,98 & \multirow{4}{*}{6 layer } & $4 \mathrm{~A}$ & 14031,5 & 359,23 \\
\hline & 1B & 3817,0 & 242,35 & & $4 \mathrm{~B}$ & 11523,5 & 295,02 \\
\hline & $1 \mathrm{C}$ & 3995,5 & 253,68 & & & & \\
\hline & Komp1 & 5691,5 & 361,37 & & Komp3 & 9322,0 & 238,66 \\
\hline
\end{tabular}

The tensile tests of Komp1 and Komp3 specimens were executed previously during the probes and the results of them are exceptionally different from the others, and just counter as it should have been waited based on the other tensile 
strength data. Without them it should be considered that the double reinforcing material supports higher load on unit surface area of cross section, but the two probe data give way to doubt. The diagrams of tensile tests have the same shape (Figs. 7, 8), after the opening convex and concave sections a long almost linear part follows until the fracture. It is interesting that the 3 layer specimens $1 \mathrm{~B}$ and Komp1 suffered Grip rupture while neither of the 6 layer specimens did it. But all of the 6-layer composite specimens broke into three parts (Double rupture).

For substantive findings, further examinations are necessary.

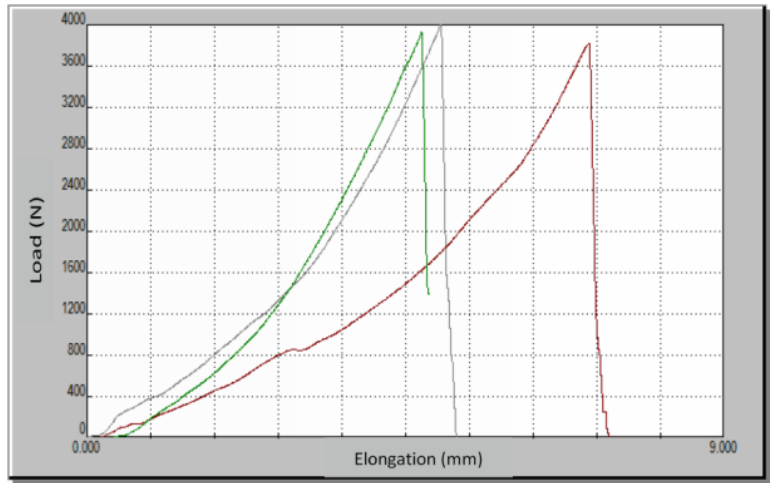

Figure 7

Tensile test diagrams of 3-layer composite specimens without fatiguing

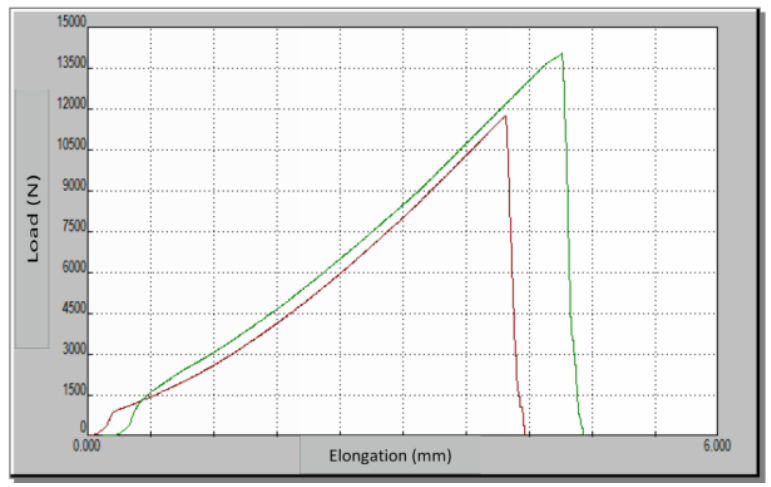

Figure 8

Tensile test diagrams of 6-layer composite specimens without fatiguing

\subsection{Tensile Tests after Fatigue}

During the fatigue tests at least 10 million bends were executed on each specimen with different stress values what the tensile tests followed. The beginning stress value was set by bending the specimen with increasing the amplitude $\left(\mathrm{r}_{\mathrm{B}}\right)$ till the resin broke then the amplitude was decreased. 
The 6-layer specimens were not useable for examining the effects of the number of reinforcing laminates for the tensile strength after fatiguing because of their specific case (see it later), so the data of the 4- and 5-layer composite specimens were compared (Table 2). There were $35 \mathrm{~mm}$ and $40 \mathrm{~mm}$ bending amplitudes in both cases and the highest tensile strengths always came from the fatigue tests with lower bending stress. But neither this, nor the number of the layers influenced significantly the tensile strength of the composites.

Table 2

Tensile test results of 4 and 5 layer specimens after fatigue tests

\begin{tabular}{|c|c|c|c|c|c|}
\hline \multirow{2}{*}{$\begin{array}{c}\text { After } \\
\text { fatigue test }\end{array}$} & Code & $\mathbf{F m}$ & $\mathbf{R m}$ & Amplitude & Bending cycles \\
\hline & & {$[\mathrm{N}]$} & {$[\mathrm{MPa}]$} & {$[\mathrm{mm}]$} & (ps) \\
\hline \multirow{2}{*}{4 layer } & $2 \mathrm{~A}$ & 7050,0 & 294 & 35 & 10384260 \\
\hline & $2 \mathrm{C}$ & 5985,5 & 252 & 40 & 13248110 \\
\hline \multirow{4}{*}{5 layer } & $3 \mathrm{~A}$ & 6914,5 & 258 & 40 & 11401760 \\
\hline & $3 B$ & 6869,0 & 251 & 40 & 12286140 \\
\hline & $3 \mathrm{C}$ & 6985,0 & 268 & 35 & 12096790 \\
\hline & $3 \mathrm{D}$ & 6799,5 & 248 & 35 & 13110910 \\
\hline
\end{tabular}

The highest tensile strength was achieved by the specimen $2 \mathrm{~A}$ which was broken with Grip rupture, alone out of the six specimens. However, this Grip rupture happened along not a straight line, but a curve connecting the neck and the gripped head of the specimen with strongly stringy rupture surface. Only one more curved Grip rupture happened during the probe tests, in case of specimen Komp1 (Fig. 6b). In both cases outstandingly high tensile strength was observed, significantly excessing their own group averages. So the Grip ruptures had to be divided into two parts: the traditional straight grip rupture (Fig. 9a) appears with average or lower tensile strength, and the curved grip rupture (Fig. 9b) brings outstanding tensile strength.
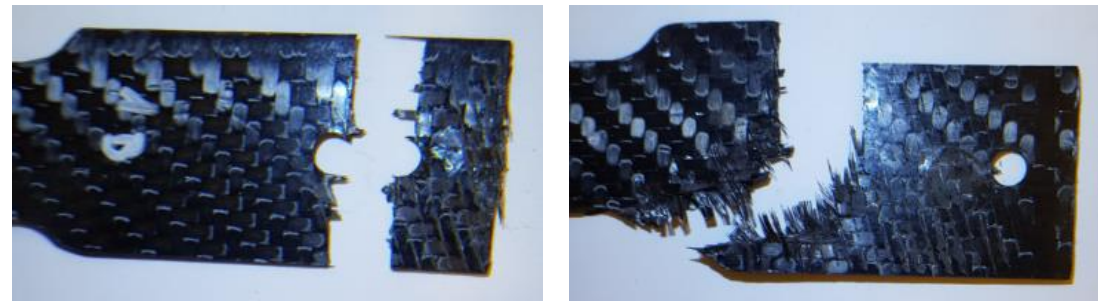

Figure 9

Straight grip rupture (9a. left), curved grip rupture (9b. right) on specimen 2A 


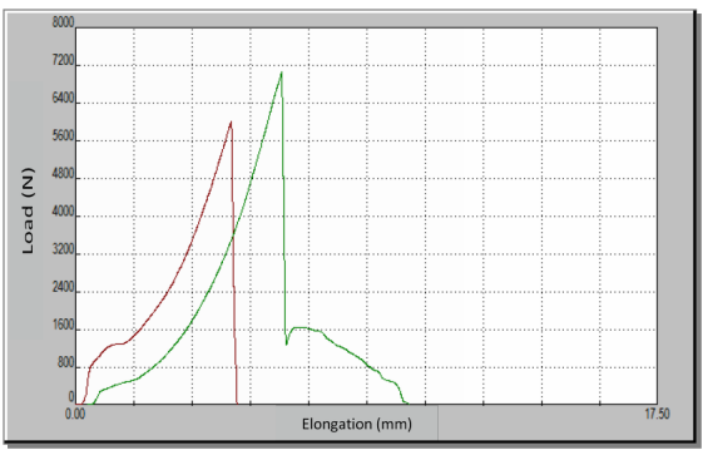

Figure 10

Tensile test diagrams of 4-layer composite specimens after fatiguing

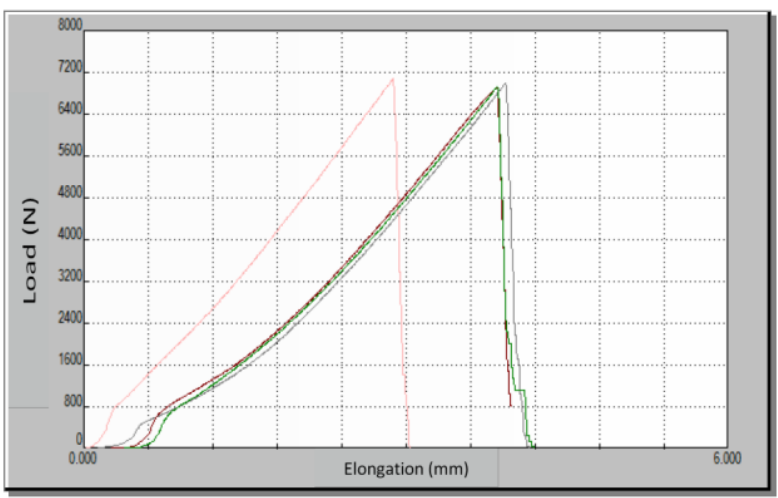

Figure 11

Tensile test diagrams of 5-layer composite specimens after fatiguing

There was no significant difference between the tensile test diagrams of the 4- and 5-layer composites (Figs. 10, 11). In both cases parallel moved diagrams are visible along the $\mathrm{X}$ axis.

Interesting result was achieved at fatigue tests of the thickest 6-layer composite specimens due to a design mistake: the reciprocating fork that bended the specimen at the opposite end to the gripped one, was too narrow and wide, so it did not let the moving end of the specimen turn accordingly to the camber of the bending. Therefore, a local bending with small radius happened at the moved neck that resulted higher stress than it occurred at the gripped neck. At this moved neck the damages were much stronger than at the other fewer layer composite specimens, which external appearances were the followings (Fig. 12):

- The wearing effect of the moving fork was clearly visible on both sides

- Cracking appeared in the resin along the reinforcing fibers on both sides

- Looking to the side it was visible that the layers partly separated 

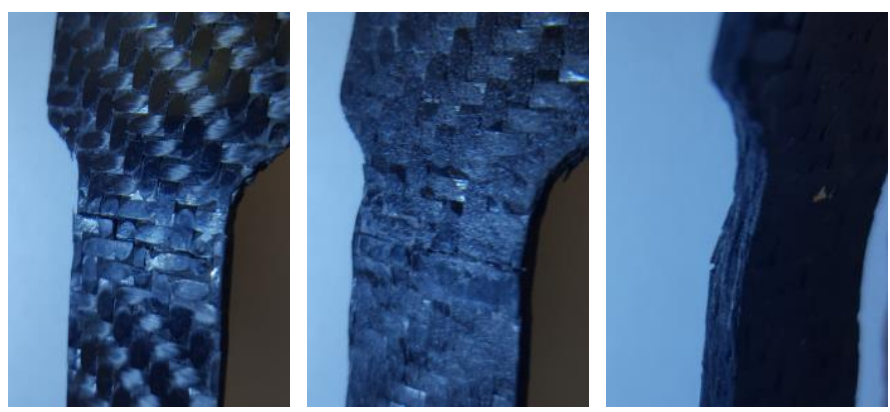

Figure 12

Fatigue damages of 6-layer composite specimen due to unplanned local load

Due to the local load the resin broke out from the fibers in small particles that led to decreased moment of second degree which is essential for bending, as there remained not enough material between the fibers that could ensure the former distance among them. The reinforcing fibers did not suffer visible damages, but during the tensile tests the specimens broke at this place one by one and at a much lower tensile strength as it would have been waited based on the results of the other tests (Figs. 13, 14).

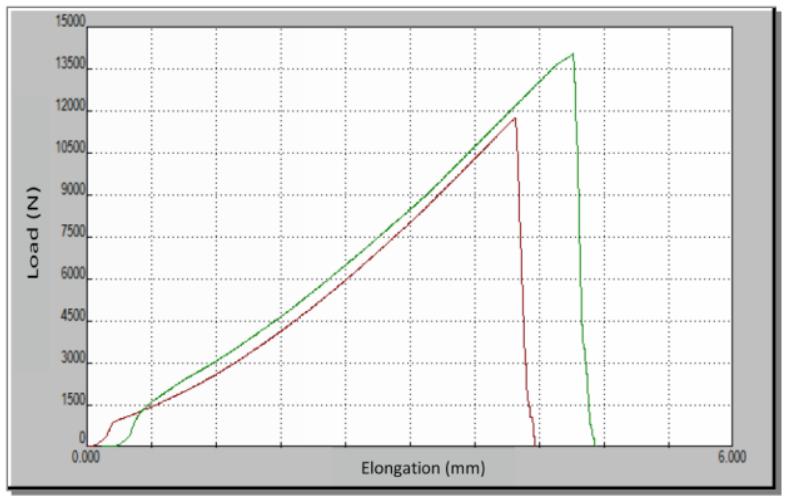

Figure 13

Tensile test diagrams of 6-layer composite specimens without fatiguing 


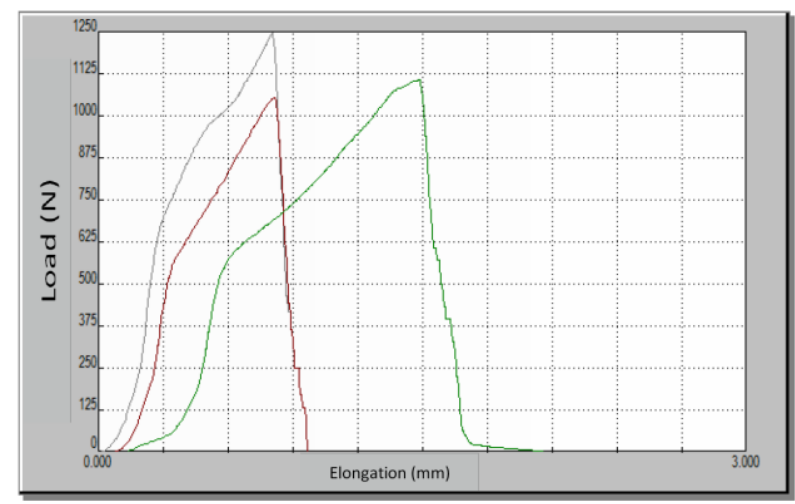

Figure 14

Tensile test diagrams of 6-layer composite specimens after fatiguing

It is visible well that the tensile strength of the damaged 6-layer composite specimen decreased to the tenth (Table 3) and there is a change in the diagram as well. The diagram of without fatiguing can be described after a short convex and concave section as a long almost linear curve, while on the diagram of after fatiguing can be observed the initial convex-concave section either (even though at lower stress and longer elongation), but this curve does not continue.

Table 3

Tensile strength of 6-layer composite specimens without and after fatiguing

\begin{tabular}{|c|c|c|c|c|c|c|c|}
\hline $\begin{array}{l}\text { Without } \\
\text { fatig. test }\end{array}$ & Code & $\begin{array}{l}\mathbf{F m} \\
{[\mathrm{N}]}\end{array}$ & $\begin{array}{c}\mathbf{R m} \\
{[\mathrm{MPa}]}\end{array}$ & $\begin{array}{c}\text { After } \\
\text { fatig. test }\end{array}$ & Code & $\begin{array}{l}\mathbf{F m} \\
{[\mathrm{N}]}\end{array}$ & $\begin{array}{c}\mathbf{R m} \\
{[\mathrm{MPa}]}\end{array}$ \\
\hline \multirow{3}{*}{6 layer } & $4 \mathrm{~A}$ & 14031,5 & 359,23 & \multirow{3}{*}{6 layer } & $4 \mathrm{~A}$ & 1105,0 & 28,29 \\
\hline & 4B & 11523,5 & 295,02 & & 4B & 1052,0 & 26,91 \\
\hline & Komp3 & 9322,0 & 238,66 & & $4 \mathrm{C}$ & 1244,0 & 31,85 \\
\hline
\end{tabular}

On the magnifications of the photos of 6-layer specimen 4B is visible (Fig. 15) that the carbon fiber fabric did not break along one edge and the longitudinal fibers turn a bit away of the parallel direction. This presumably means that the reinforcing fibers did not break uniformly at once, but separately one after the other. On the right, optically filtered picture it can be observed that far from the fracture (on the right side of the photo) the black spots (adhesions to the form by vacuum-infusion) shows coherent appearance (they are all in one plane), but approaching the fracture this order is loosened, the planes are deforming. 

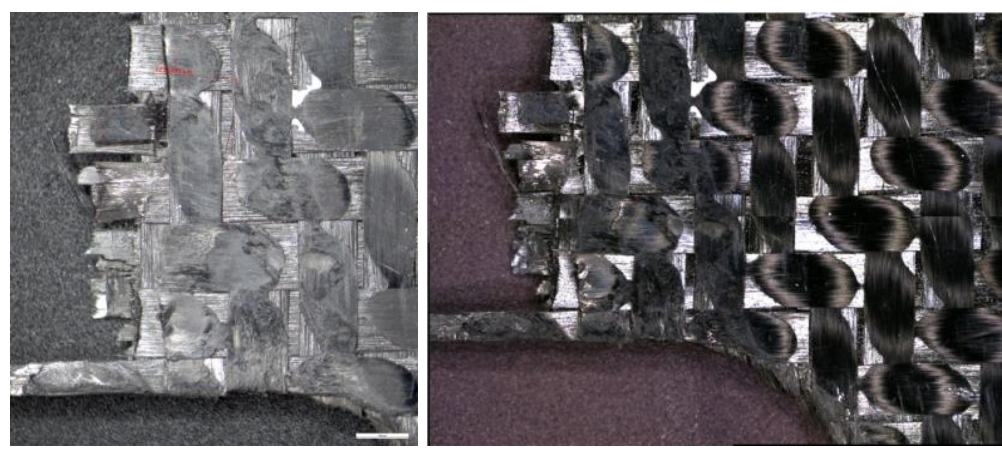

Figure 15

Tensile fracture of a 6-layer specimen after fatiguing, by diffused light (left), optically filtered (right)

If it is still considered on the basis of adequate bibliography that the carbon fibers are resistant to fatigue, the lower tensile strength had to be caused by the resin fracture. Either the resin particles damaged the carbon fibers (by wearing or sharp edges), or the carbon fibers each other, or the load-share of the resin was missing, or two or more worked together causing the very low tensile strength.

\section{Conclusions}

In this project, the aim was to fatigue test carbon fiber composite materials with differing numbers of reinforcing laminates embedded in epoxy resin. First, a bending fatigue test machine, with a crank mechanism was developed and manufactured. The devise was also optimized for partly dynamic loads. Afterwards, half of the in-house produced specimens, were examined by fatigue and tensile tests, the other half, only tensile tests. Interesting ruptures were detected, categorized and named as Grip ruptures, Neck ruptures, Whiskers ruptures and Double ruptures. Grip ruptures were divided into two groups: straight rupture with normal tensile strength and curved rupture with higher strength. Within the control group, without fatiguing, all of the thickest (6-layer) specimens broke into three parts, during the tensile tests. In accordance with the literature, the fatigue limit was undetectable in cases of the 3-5 reinforcing layers, the thickness did not influence, significantly, the tensile strength per unit surface. In the 6-layer composite material's fatigue tests, the bending fork caused an unplanned excess load, that produced an interesting result: Cracks appeared in the resin along the reinforcing fibers, the cross section of the specimen reduced and the tensile strength (counted with the original cross-section) decreased to a tenth.

\section{Acknowledgement}

This work has been supported by the European Union, co-financed by the European Social Fund. EFOP-3.6.1-16-2016-00014. Authors are thankful for it. 


\section{References}

[1] Friedrich K., Fakirov S., Zhang Z.: Polymer Composites. Springer US, Boston (2005)

[2] Trewin E.: The advanced composites industry - Global markets, technology trends and applications. Materials Technology Publications, Watford, UK (2003)

[3] Forsdyke K. L., Starr T. F.: Thermoset resins- Market Report. , Shawbury, (2002)

[4] Shaw T. M., MacKnight J. W.: Introduction to Polymer Viscoelasticity. Wiley, New York (2005)

[5] Starkova O., Buschhorn S. T., Mannov E., Schulte K., Aniskevich A.: Creep and recovery of epoxy/MWCNT nanocomposites. Composites Part A: Applied Science and Manufacturing, 43, 1212-1218 (2012)

[6] Harris B.: Fatigue in composites. Woodhead Publishing, Cambridge (2003)

[7] Horst J. J., Spoormaker J. L.: Fatigue fracture mechanisms and fractography of shortglassfibre-reinforced polyamide 6 . Journal of Materials Science, 32, 3641-3651 (1997)

[8] Ueki Y.: High-speed bending-fatigue testing of composite materials, IOP Publishing, IOP Conf. Series: Materials Science and Engineering 388, 012008 (2018)

[9] P. V. Kulkarni, P. J. Sawant, V. V. Kulkarni: Design and Development of Plane Bending Fatigue Testing Machine for Composite MaterialMaterials Today: Proceedings 5, 11563-11568 (2018)

[10] W. Van Paepegem, J. Degrieck: Experimental setup for and numerical modelling of bending fatigue experiments on plain woven glass/epoxy composites, Composite Structures, 51(1), 1-8, (2001)

[11] S. M. Landge, Patil D. N., Talekar A. V., Ghosh A. A., Prof. Mr. Mainak Bhaumik M.: Design \& Development of Bending Fatigue testing Machine for Composite Materials, International Research Journal of Engineering and Technology (IRJET) 05, 04 (2018) 